Research Article

\title{
Experimental Study on Special Testing Strength Curve for Compressive Strength Evaluation by Rebound Method
}

\author{
Wei Yuan $\mathbb{D}^{1},{ }^{1}$ Renfeng Yang, ${ }^{1}$ Jianyou Yu, ${ }^{2}$ and Xiujie Han ${ }^{2}$ \\ ${ }^{1}$ School of Construction Machinery, Chang'an University, Xi'an, Shaanxi 710064, China \\ ${ }^{2}$ Yan-Chong Temporary Preparatory Office of Hebei Province Expressway, Zhang Jiakou, Hebei 075400, China \\ Correspondence should be addressed to Wei Yuan; 2018025012@chd.edu.cn
}

Received 6 September 2021; Revised 27 September 2021; Accepted 26 October 2021; Published 3 November 2021

Academic Editor: Shengwen Tang

Copyright (c) 2021 Wei Yuan et al. This is an open access article distributed under the Creative Commons Attribution License, which permits unrestricted use, distribution, and reproduction in any medium, provided the original work is properly cited.

This article aims to improve the accuracy and predictability of rebound method in compressive strength evaluation of concrete members of the Yanchong Expressway, which is an important traffic guarantee project for the 2022 Winter Olympics Games in Zhangjiakou city, Hebei Province, China. For this purpose, concrete specimens were prepared by the mixing ratios of C35, C40, and C50. First of all, the paper investigated the effects of curing age, types, and dosage of mineral admixtures (fly ash and slag) on concrete rebound number and compressive strength. Then, the special testing strength curves of $7 \mathrm{~d}$ and $90 \mathrm{~d}$ curing age were proposed. The results showed that the average relative errors of the special testing strength curves were reduced by $35.99 \%$ and $20.26 \%$ respectively, compared with the national testing strength curve. Fly ash and slag were beneficial to the growth of concrete rebound numbers but cannot contribute to the growth of concrete compressive strength (except for fly ash single-mixed with $15 \%$ dosage). The present results can provide a significant reference for the compressive strength evaluation and later maintenance of concrete members of the Yanchong Expressway or other projects with tight construction period in this area.

\section{Introduction}

Rebound method plays a vital role in not only the quality control of new concrete construction but also the strength evaluation of existing concrete structures [1]. The rebound hammer test is primarily used in common engineering practice among the nondestructive technique's procedures because of its simplicity, speed, and low equipment price [2-5]. Currently, the most widely used rebound hammers were developed by the Swiss scientist Ernst Schmidt $[6,7]$. The rebound numbers can be obtained from the rebound when the rebound hammer impacted the concrete surface with defined energy, reflecting the concrete strength with an acceptable error [1].

In the last few years, many researchers have investigated the relationship between rebound number and compressive strength of concrete in the form of equations and graphs. The compressive strength regression model is estimated according to the rebound numbers, which is called a "testing strength curve" [1]. Pereira and Romão [8] presented a power function models relationship between rebound number and compressive strength, particularly in existing structures where the strength variation coefficient is expected to be above $10 \%$. Rashid and Waqas [9] proposed a second-order polynomial model instead of a power model with a wide range of outcomes. Samson and Omoniyi [10] demonstrated that for all grades of concrete, the higher the rebound number is, the higher the compressive strength is, and vice versa. However, previous studies also found that the compressive strength regression model, which is established by the rebound hammer method, is affected by the concrete surface (such as the degree of saturation, carbonation, temperature, and surface finish), type of aggregate and cement, mix proportions, and curing conditions $[1,11-16]$. Niş proposed that the curing methods and duration significantly change the compressive strength of the specimens even in the novel construction materials [17]. Kocab et al. [2] thought that inaccurate results will be produced if the general regression model is used to estimate the compressive strength. Szilágyi et al. [7] objected to directly correlating the 
average rebound number with compressive strength as univariate functions and argued for "a series of multivariate functions with independent variables of the degree of hydration, type and amount of cement and aggregate, environmental conditions, and testing conditions." Kumavat et al. [11] considered that the regression models based on the laboratory test might be valid within their implementation boundaries for estimating the compressive strength of concrete. Brencich et al. [4] suggested that the conception of a universal calibration curve for any concrete does not exist under any conditions. Thus, some research had been devoted to studying the special testing strength curve for regional engineering or special projects. Tan et al. [1] proposed the $28 \mathrm{~d}$ and $90 \mathrm{~d}$ testing strength curves for coral aggregate concrete in specific engineering by rebound hammer. Liu et al. [18] defined the special concrete strength curves for the Oujiang River Bridge based on the test results with ZC3-A regular rebound hammer and H450 high-strength rebound hammer. Vatani Oskouei et al. [19] developed the concrete strength predictive model for concrete face rockfill dams in Bijar (Gilan province) by analyzing the relationship between rebound number and compressive strength. Accordingly, it is quite meaningful to develop a regression model, considering both the rebound number and compressive strength for a specific project, and to improve the accuracy of the rebound method in predicting the compressive strength of concrete structure.

Yanchong Expressway is an important traffic guarantee project for the 2022 Winter Olympics Games, which is located in Zhangjiakou city, Hebei Province, China. Zhangjiakou city is a typical seasonal freezing zone with the minimum temperature of $-32^{\circ} \mathrm{C}$ and the maximum temperature of $42.2^{\circ} \mathrm{C}$. The dual effects of extremely low temperature and freezingthawing cycles demands more on the construction quality of concrete structures. However, the project's construction period is only 28 months, the bridge-tunnel ratio is $56.4 \%$, and the practical construction period is extremely short. In the construction process, it is often vital to know the compressive strength of concrete structures at an early age, which is the strength to remove the formwork safely, also known as stripping strength [2]. Based on those studies, the paper studied the effects of curing age, mineral admixtures content, and admixing method on the rebound number and compressive strength of concrete. The $7 \mathrm{~d}$ and $90 \mathrm{~d}$ testing strength curves for concrete members of Yanchong Expressway were established according to Technical Specification for Inspection of Concrete Compressive Strength by Rebound Method, JGJ/T 23-2011 [20]. The present results can provide a significant reference for the accuracy of compressive strength assessment by the rebound method.

\section{Materials and Experiments}

2.1. Materials. In this paper, all raw materials of concrete specimens are the same as those used for concrete members of the Yanchong Expressway, which are Chinese standard 425\# ordinary Portland cement, produced by Hebei Zhuolu Jinyu Cement Co., Ltd. in China (its basic physical properties are listed in Table 1); Class F and level-I fly ash, which was also produced by Zhangjiakou Jinyu Cement Co., Ltd.; and $\$ 95$ grade slag, which was produced by Hebei Jidong Cement Corporation in China. The basic properties of used fly ash and slag are listed in Table 2 . Fine aggregates with a fineness modulus of 2.86 and coarse aggregate (diameter ranging from $5 \mathrm{~mm}$ to $20 \mathrm{~mm}$ ) are local natural sources or crushed hard limestone. The high-range water reducer used in the experiment was a superplasticizer based on polycarboxylate (FSS-PC) with the water reduction is $27 \%$, which was supplied by Hebei Qinghua Building Materials Co., Ltd.

2.2. Specimens Preparation. According to Chinese standard JGJ/T 23-2011 [20], three sets of C35, C40, and C50 concrete cubes $(150 \mathrm{~mm} \times 150 \mathrm{~mm} \times 150 \mathrm{~mm})$ were prepared. In order to investigate the influence of mineral admixtures content and admixing method on the rebound number and compressive strength of concrete, specimens were prepared by changing the dosage of mineral admixtures with $\mathrm{C} 50$, and the mixture proportions are shown in Table 3. The specimens were casted in plastic molds with external vibration for compacted and demolded $24 \mathrm{~h}$ later. After the specimens were removed from the mold, they were further cured at the bridge construction site for 7 days, 14 days, 28 days, 60 days, and 90 days, respectively.

2.3. Test Methods. ZC3-A rebound hammer was used in the rebound method in this paper, and the rebound hammer test was conducted according to JGJ/T 23-2011. Each of the two opposite sides of the specimen were selected for the rebound hammer test. The specimen was positioned in a DYE-2000 hydraulic press, and a small load $(80 \sim 100 \mathrm{kN})$ was applied. Eight points of each side of the specimen were measured, and the three maximum and three minimum number were abandoned, and then the mean of 10 points were counted as the rebound number. Because the result was affected by the inclination of the hammer, the rebound hammer was horizontal in all measurements. When each specimen was completed by rebound method, the specimen was continuously pressurized until it is damaged. Then, the destructive compressive strength was recorded. Figure 1 shows the rebound hammer test and compressive strength test of concrete specimens.

2.4. Verification of Testing Strength Curve. The average relative error $(\delta)$ and relative standard error $\left(e_{r}\right)$ are used to verify the applicability of the testing strength curve to the strength evaluation for practical engineering. The calculation equations of $\delta$ and $e_{r}$ are as follows [20]:

$$
\begin{aligned}
& \delta= \pm \frac{1}{n} \sum_{i=1}^{n}\left|\frac{f_{\mathrm{cu}, i}}{f_{\mathrm{cu}, i}^{c}}-1\right| \times 100, \\
& e_{r}=\sqrt{\frac{1}{n-1} \sum_{i=1}^{n}\left(\frac{f_{\mathrm{cu}, i}}{f_{\mathrm{cu}, i}^{c}}-1\right)^{2}} \times 100,
\end{aligned}
$$


Table 1: Basic physical properties of used 425\# ordinary Portland cement.

\begin{tabular}{|c|c|c|c|c|c|c|c|c|c|}
\hline \multirow[t]{2}{*}{ Cement } & \multirow[t]{2}{*}{ Specific surface area $\left(\mathrm{m}^{2} / \mathrm{kg}\right)$} & \multirow[t]{2}{*}{ Consistency (\%) } & \multirow[t]{2}{*}{ Loss of ignition (\%) } & \multicolumn{2}{|c|}{$\begin{array}{l}\text { Setting time } \\
\quad(\min )\end{array}$} & \multicolumn{2}{|c|}{$\begin{array}{l}\text { Compressive } \\
\text { strength } \\
(\mathrm{MPa})\end{array}$} & \multicolumn{2}{|c|}{$\begin{array}{c}\text { Flexural } \\
\text { strength } \\
(\mathrm{MPa})\end{array}$} \\
\hline & & & & Initial & Final & $3 \mathrm{~d}$ & $28 \mathrm{~d}$ & $3 \mathrm{~d}$ & $28 \mathrm{~d}$ \\
\hline P.O 42.5 & 375 & 28.2 & 2.4 & 191 & 241 & 30.1 & 54.4 & 5.7 & 7.6 \\
\hline
\end{tabular}

TABLE 2: Basic properties of used fly ash and slag.

\begin{tabular}{lcccccccc}
\hline $\begin{array}{l}\text { Mineral } \\
\text { admixtures }\end{array}$ & $\begin{array}{c}\text { Water requirement } \\
\text { ratio (\%) }\end{array}$ & $\begin{array}{c}\text { Water } \\
\text { content (\%) }\end{array}$ & $\begin{array}{c}\text { Loss of } \\
\text { ignition (\%) }\end{array}$ & Density $\left(\mathrm{g} / \mathrm{cm}^{3}\right)$ & $\mathrm{Cl}^{-}(\%)$ & $\mathrm{SO}_{3}(\%)$ & Fineness (\%) & Free calcium oxide (\%) \\
\hline Fly ash & 92 & 0.25 & 4.4 & 2.54 & 0.011 & 0.91 & 10.6 & 0.9 \\
Slag & 97 & 0.2 & 0.75 & 2.99 & 0.016 & 0.15 & - & - \\
\hline
\end{tabular}

TABLE 3: Mixture proportion of concrete specimens $\left(\mathrm{kg} / \mathrm{m}^{3}\right)$.

\begin{tabular}{|c|c|c|c|c|c|c|c|c|}
\hline & Mix & Cement & Sand & Coral aggregate & Water & Fly ash & Slag & FSS-PC \\
\hline $\mathrm{C} 35$ & & 320 & 787 & 1087 & 156 & 40 & 40 & 4.0 \\
\hline $\mathrm{C} 40$ & & 356 & 735 & 1103 & 156 & 45 & 45 & 4.46 \\
\hline \multirow[t]{2}{*}{ C50 } & & 392 & 705 & 1103 & 152 & 49 & 49 & 5.88 \\
\hline & Slag $15 \%$ & 416.5 & 705 & 1103 & 152 & 0 & 73.5 & 5.88 \\
\hline \multirow[t]{3}{*}{ C50 } & Slag $30 \%$ & 343 & 705 & 1103 & 152 & 0 & 147 & 5.88 \\
\hline & Slag $45 \%$ & 269.5 & 705 & 1103 & 152 & 0 & 220.5 & 5.88 \\
\hline & Fly ash15\% & 416.5 & 705 & 1103 & 152 & 73.5 & 0 & 5.88 \\
\hline \multirow[t]{3}{*}{ C50 } & Fly ash $20 \%$ & 392 & 705 & 1103 & 152 & 98 & 0 & 5.88 \\
\hline & Fly ash $30 \%$ & 343 & 705 & 1103 & 152 & 147 & 0 & 5.88 \\
\hline & Fly ash $15 \%+$ slag $15 \%$ & 343 & 705 & 1103 & 152 & 73.5 & 73.5 & 5.88 \\
\hline \multirow{3}{*}{ C50 } & Fly ash $15 \%+$ slag $30 \%$ & 269.5 & 705 & 1103 & 152 & 73.5 & 147 & 5.88 \\
\hline & Fly ash $20 \%+$ slag $15 \%$ & 318.5 & 705 & 1103 & 152 & 98 & 73.5 & 5.88 \\
\hline & Fly ash $30 \%+$ slag $15 \%$ & 269.5 & 705 & 1103 & 152 & 147 & 73.5 & 5.88 \\
\hline
\end{tabular}

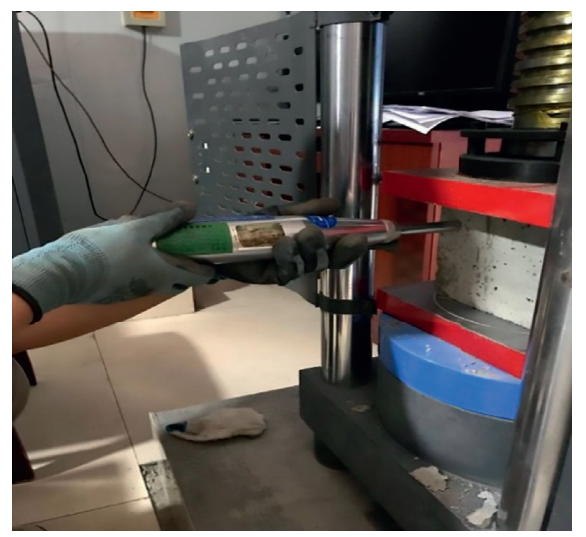

(a)

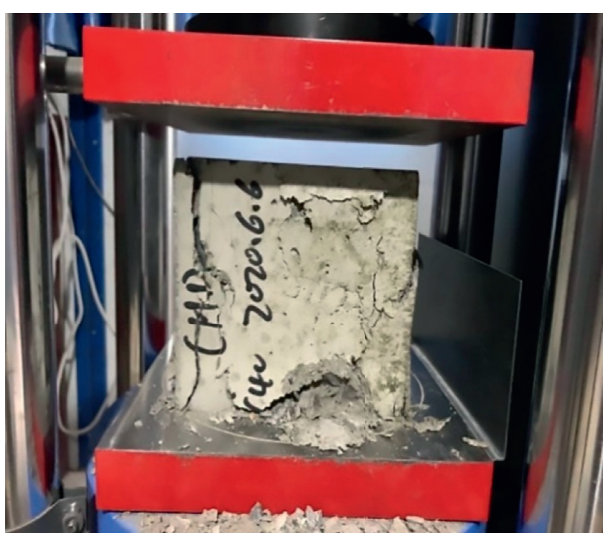

(b)

FIGURE 1: The rebound hammer test and compressive strength test of concrete specimens: (a) rebound hammer test and (b) destructive compressive strength test.

where $\delta$ is the average relative error, $e_{r}$ is the relative standard error, $n$ is the amount of specimen fabricated, $f_{\mathrm{cu}, i}$ is the compressive strength value gained from failure specimen, and $f_{\mathrm{cu}, i}^{c}$ is the conversion value of the compressive strength obtained from testing strength curve. According to the specification of JGJ/T 23-2011 (rebound hammer method), the errors of $\delta$ and $e_{r}$ for special projects testing strength curve are $\delta \leq 12 \%$ and $e_{r} \leq 14 \%$, respectively. 


\section{Results and Discussion}

3.1. Rebound Number and Compressive Strength of C35, C40, and C50 Concrete at Various Curing Ages. The influence of various curing ages on the rebound number and compressive strength of C35, C40, and C50 concrete is presented in Figure 2.

The results can be drawn from Figure 2 as follows. The rebound number and compressive strength of different concrete grades increase with the growth of the curing age. In different curing stages, the growth rate of rebound number and compressive strength of concrete is different. The first curing stage of concrete is as follows $(0 \sim 7 \mathrm{~d})$ : the growth rate of concrete rebound number and compressive strength are faster in this period. The rebound number of C35, C40, and C50 concrete at the curing age of $7 \mathrm{~d}$ is $40.93 \mathrm{MPa}, 44.55 \mathrm{MPa}$, and 44.46 $\mathrm{MPa}$, respectively, and the compressive strength is $40.73 \mathrm{MPa}, 47.92 \mathrm{MPa}$, and $54.82 \mathrm{MPa}$, respectively, indicating that the concrete has prominent early strength characteristics. Therefore, the early curing stage is the main formation period of concrete strength. More attention should be paid to whether the curing conditions of concrete members meet the requirements at the early curing stages. The second curing stage of concrete is as follows (7 14 d): the growth rate of concrete compressive strength is significantly higher than that of rebound number. The third curing stage of concrete is as follows $(14 \sim 28 \mathrm{~d})$ : the growth rate of rebound number and compressive strength of concrete gradually slow down with the extension of curing age. Compared with the curing age of $7 \mathrm{~d}$, the rebound number of $\mathrm{C} 35, \mathrm{C} 40$, and $\mathrm{C} 50$ concrete at $28 \mathrm{~d}$ increases by $5.7 \%, 6.8 \%$, and $9.0 \%$, respectively, and the compressive strength increases by $18.2 \%, 18.8 \%$, and $18.8 \%$, respectively. The fourth curing stage of concrete is as follows (28 90 d): the rebound number of C35, C40, and C50 concrete at the curing age of $90 \mathrm{~d}$ is $48.26 \mathrm{MPa}, 50.30 \mathrm{MPa}$, and $51.15 \mathrm{MPa}$, respectively, and the compressive strength is 55.27 MPa, 59.67 MPa, and 70.31 MPa, respectively. Compared with the third curing stage of concrete, the growth rate of rebound number and compressive strength continued to slow down.

3.2. Rebound Number and Compressive Strength of C50 Concrete Single-Mixed with Slag at Various Curing Ages. Figure 3 shows the rebound number and compressive strength of C50 concrete single-mixed with slag at various curing ages.

The results can be drawn from Figure 3 as follows. The rebound number and compressive strength of C50 concrete single-mixed with slag dosages of $15 \%, 30 \%$, and $45 \%$ increase with the extension of curing age, and all of them decrease with the increase of slag dosages. The first curing stage of concrete is as follows $(0 \sim 7 \mathrm{~d})$ : the rebound number of concretes single-mixed with slag dosages of $15 \%, 30 \%$, and $45 \%$ is $48.8 \mathrm{MPa}, 47.6 \mathrm{MPa}$, and $44.8 \mathrm{MPa}$, respectively, at the curing age of $7 \mathrm{~d}$, and the compressive strength is 55.1 $\mathrm{MPa}, 56.2 \mathrm{MPa}$, and 49.1 $\mathrm{MPa}$, respectively. The second curing stage of concrete is as follows (7 14d): the growth rate of concrete compressive strength is significantly higher than that of rebound number. The third curing stage of concrete is as follows $(14 \sim 28 \mathrm{~d})$ : the growth rate of rebound number and compressive strength of concrete gradually slow down with the extension of curing age. Compared with the curing age of $7 \mathrm{~d}$, the rebound number of concretes singlemixed with slag $15 \%, 30 \%$, and $45 \%$ at the curing age of $28 \mathrm{~d}$ increases by $3.38 \%, 2.73 \%$, and $8.47 \%$, respectively, and the compressive strength increases by $16.62 \%, 11.11 \%$, and $22.66 \%$, respectively. The fourth curing stage of concrete is as follows (28 90 d): the rebound number of concretes singlemixed with slag dosages of $15 \%, 30 \%$, and $45 \%$ is $50.8 \mathrm{MPa}$, $50.2 \mathrm{MPa}$, and $49.8 \mathrm{MPa}$, respectively, and the compressive strength is $67.2 \mathrm{MPa}, 65.4 \mathrm{MPa}$, and $64.6 \mathrm{MPa}$, respectively, at the curing age of $90 \mathrm{~d}$. Compared with the third curing stage of concrete, the growth rate of rebound number and compressive strength of concrete tend to be stable.

Compared with the C50 concrete used in the project, the rebound number of the concrete single-mixed with slag $15 \%$, $30 \%$, and $45 \%$ increases by $9.67 \%, 7.13 \%$, and $0.92 \%$, respectively, at the curing age of $7 \mathrm{~d}$. The compressive strength of concrete single-mixed with slag $15 \%$ and $30 \%$ increases by $0.33 \%$ and $2.63 \%$, while the compressive strength of concrete single-mixed with slag $45 \%$ decreases by $10.4 \%$, respectively. At the curing age of $28 \mathrm{~d}$, the rebound number of concretes single-mixed with slag $15 \%, 30 \%$, and $45 \%$ increases by $4.06 \%, 0.87 \%$, and $0.39 \%$, respectively, while the compressive strength of concrete decreases by $1.52 \%, 4.02 \%$, and $7.57 \%$. At the curing age of $90 \mathrm{~d}$, the rebound number of concretes single-mixed with slag $15 \%, 30 \%$, and $45 \%$ decreases by $0.78 \%, 1.94 \%$, and $2.64 \%$, respectively, and the compressive strength of concrete decreases by $4.45 \%, 7.01 \%$, and $8.15 \%$.

It shows that slag is beneficial to improve the early rebound number of concretes, but it has an inhibitory effect on the compressive strength of concrete. In the later curing stage, the weakening of the rebound number of concretes single-mixed with slag is less than the compressive strength.

\subsection{Rebound Number and Compressive Strength of C50} Concrete Single-Mixed with Fly Ash at Various Curing Ages. Figure 4 shows the influence of various curing ages on the rebound number and compressive strength of C50 concrete single-mixed with fly ash.

The results can be drawn from Figure 4 as follows. The rebound number and compressive strength of concrete single-mixed with fly ash dosages of $15 \%, 20 \%$, and $30 \%$ increase with the extension of curing age, and all of them decrease with the increase of fly ash dosages. The first curing stage of concrete is as follows $(0 \sim 7 \mathrm{~d})$ : the rebound number of concretes single-mixed with fly ash dosages of $15 \%, 20 \%$, and $30 \%$ is $46.5 \mathrm{MPa}, 46.2 \mathrm{MPa}$, and $46.1 \mathrm{MPa}$, respectively, at the $7 \mathrm{~d}$ curing age, and the compressive strength is 53.1 $\mathrm{MPa}, 53.0 \mathrm{MPa}$, and 53.1 $\mathrm{MPa}$, respectively. The second curing stage of concrete is as follows $(7 \sim 14 \mathrm{~d})$ : the growth rate of concrete compressive strength is significantly higher than that of rebound number. The third curing stage of concrete is as follows (14 28 d): the growth rate of concrete rebound number and compressive strength are faster. 


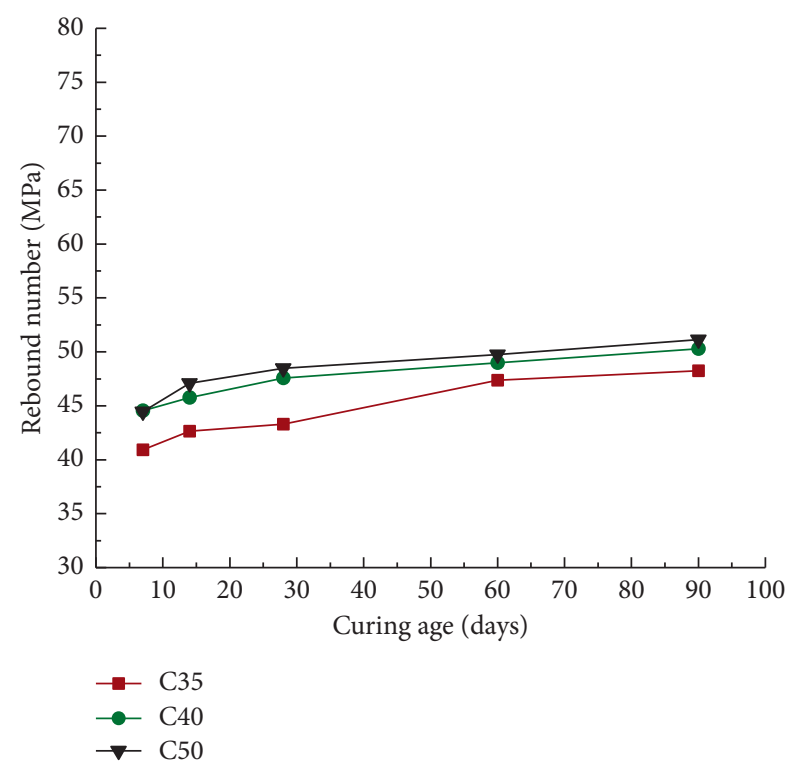

(a)

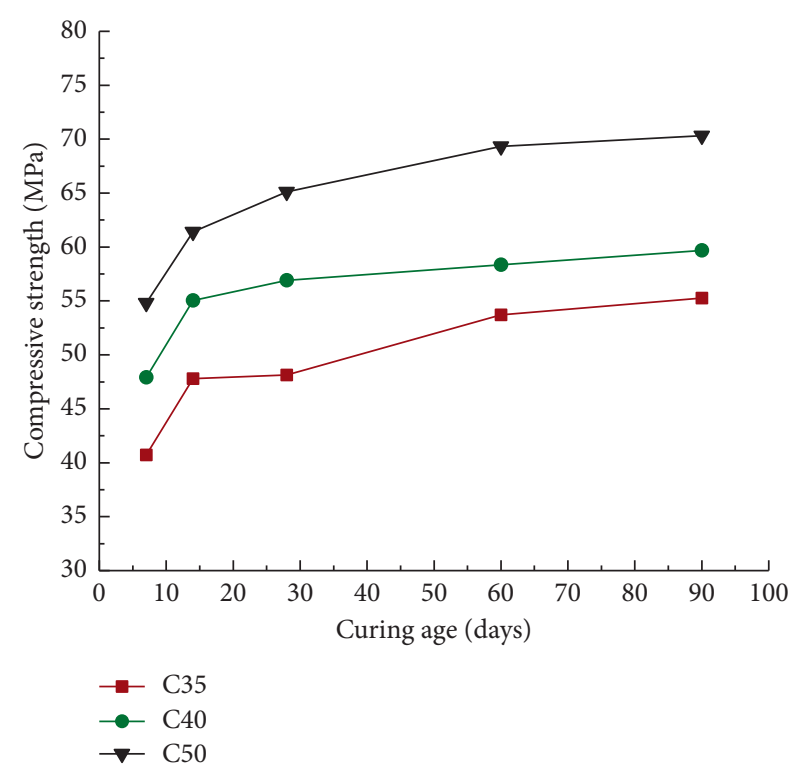

(b)

FIGURE 2: Rebound number and compressive strength of concrete mixing proportion of C35, C40, and C50 at various curing ages: (a) rebound number and (b) compressive strength.

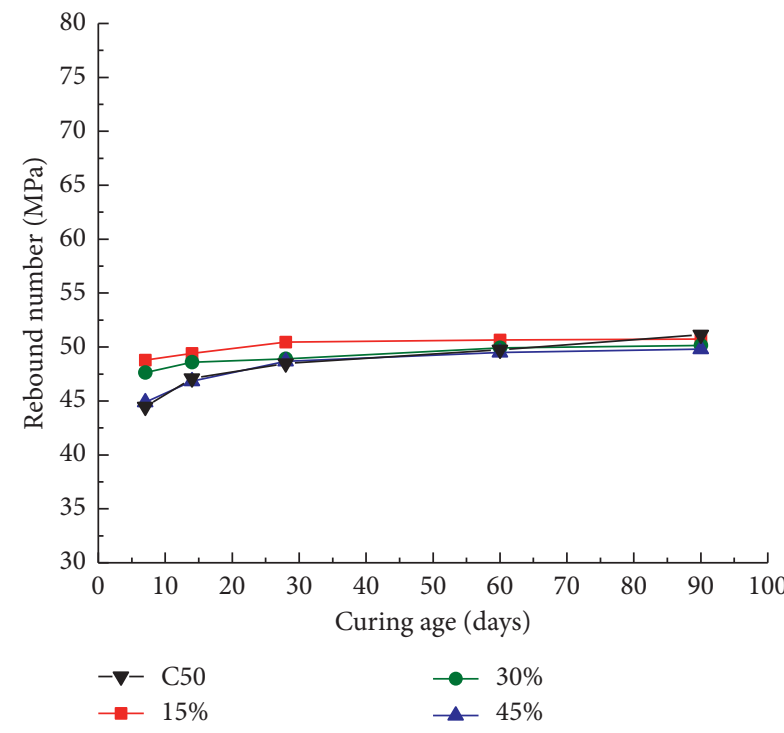

(a)

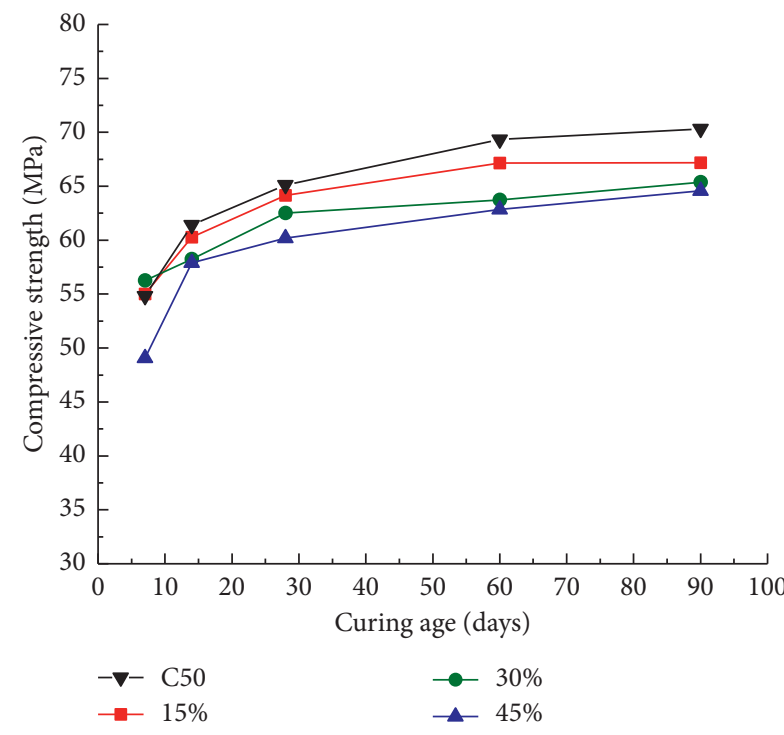

(b)

FIGURE 3: Rebound number and compressive strength of C50 concrete single-mixed with slag at various curing ages: (a) rebound number and (b) compressive strength.

Compared with the $7 \mathrm{~d}$ curing age, the rebound number of concretes single-mixed with fly ash $15 \%, 20 \%$, and $30 \%$ at $28 \mathrm{~d}$ increases by $8.82 \%, 7.79 \%$, and $6.18 \%$, respectively, and the compressive strength increases by $24.80 \%, 13.90 \%$, and $9.32 \%$, respectively. The fourth curing stage of concrete is as follows (28 90 d): the rebound number of concretes singlemixed with fly ash dosages of $15 \%, 20 \%$, and $30 \%$ is $51.2 \mathrm{MPa}$ and $51.3 \mathrm{MPa}$ at $90 \mathrm{~d}$ curing age and $50.8 \mathrm{MPa}$, respectively, and the compressive strength is $75.4 \mathrm{MPa}, 68.4 \mathrm{MPa}$, and 63.1 MPa, respectively. Additionally, the rebound number of the concrete single-mixed with fly ash dosages of $20 \%$ and $30 \%$ has slightly increased during $60 \mathrm{~d} \sim 90 \mathrm{~d}$ curing age. However, there is no significant difference when the fly ash dosage up to $90 \mathrm{~d}$, and the compressive strength tends to be stable.

Compared with the C50 concrete used in the project, the rebound number of the concrete single-mixed with fly ash $15 \%, 20 \%$, and $30 \%$ increases by $4.59 \%, 3.88 \%$, and $3.80 \%$, respectively, at $7 \mathrm{~d}$ curing age; the compressive strength decreases by $3.10 \%, 3.17 \%$, and $3.12 \%$, respectively. At $28 \mathrm{~d}$ 


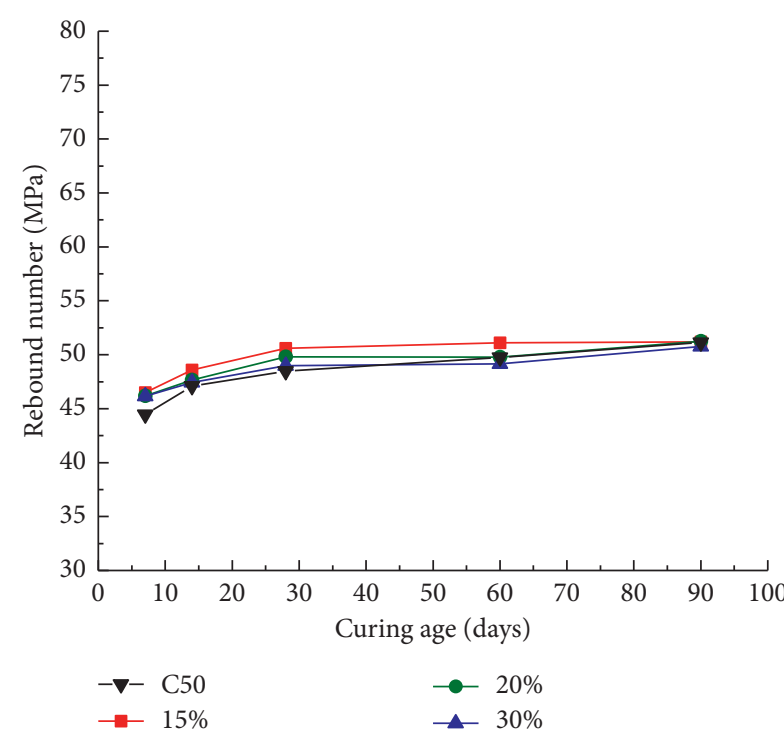

(a)

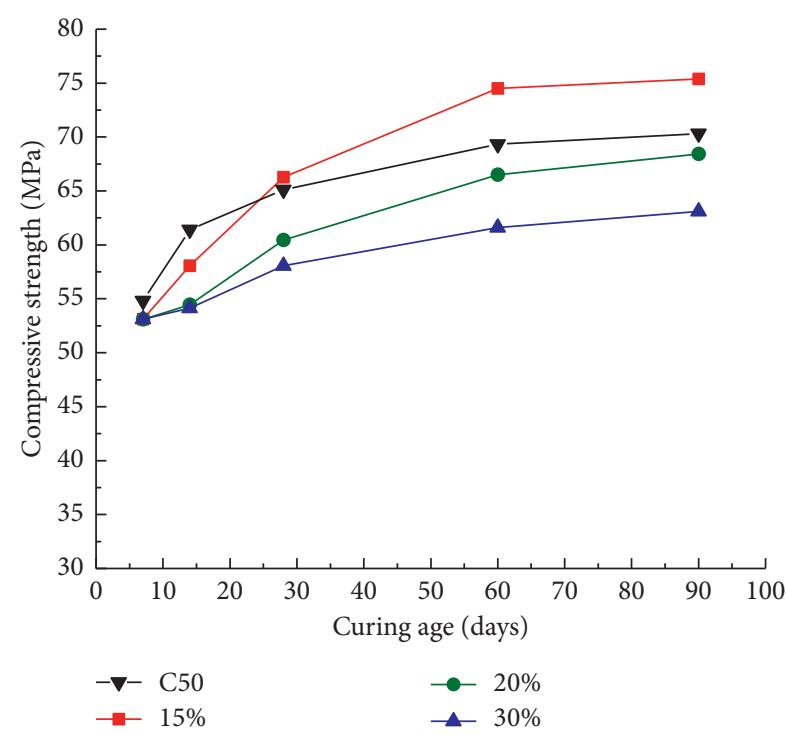

(b)

FIGURE 4: Rebound number and compressive strength of C50 concrete single-mixed with fly ash at various curing ages: (a) rebound number and (b) compressive strength.

curing age, the rebound number of concretes single-mixed with fly ash $15 \%, 20 \%$, and $30 \%$ increases by $4.37 \%, 2.76 \%$, and $1.07 \%$, respectively, and the compressive strength of concrete single-mixed with fly ash dose $15 \%$ increases by $1.75 \%$, while the compressive strength of concrete singlemixed with fly ash dose $20 \%$ and $30 \%$ decreases by $7.17 \%$ and $10.86 \%$, respectively. At $90 \mathrm{~d}$ curing age, the rebound number of concretes under each fly ash dosage are equal to that of the C50 concrete in the project. The compressive strength of concrete single-mixed with fly ash $15 \%$ increases by $7.24 \%$, and the compressive strength of concrete singlemixed with fly ash $20 \%$ and $30 \%$ decreases by $2.68 \%$ and $10.25 \%$, respectively.

Therefore, fly ash is beneficial to improve the early rebound number of concretes, while the compressive strength of concrete can be improved only when fly ash content is $15 \%$, which is in good agreement with other studies $[14,21]$.

3.4. Rebound Number and Compressive Strength of C50 Concrete Double-Mixed with Fly Ash and Slag at Various Curing Ages. The influence of various curing ages on the rebound number and compressive strength of C50 concrete double-mixed with fly ash and slag is shown in Figure 5.

The results can be drawn from Figure 5 as follows. The growth rate of rebound number and compressive strength of concrete double-mixed with fly ash and slag dosages of $15 \%$ $15 \%, 15 \% 30 \%, 20 \% 15 \%$, and $30 \% 15 \%$ increase with the extension of curing age. The concrete specimens, which are double-mixed with fly ash and slag dosages of $15 \% 30 \%$ and $30 \% 15 \%$, have a significant effect on the growth of the early rebound number and compressive strength of concrete. The first curing stage of concrete is as follows $(0 \sim 7 \mathrm{~d})$ : the rebound number of concretes double-mixed with fly ash and slag dosages of $15 \% 15 \%, 15 \% 30 \%, 20 \% 15 \%$, and $30 \% 15 \%$ is
45.4 MPa, 42.4 MPa, 46.7 $\mathrm{MPa}$, and $41.7 \mathrm{MPa}$ at $7 \mathrm{~d}$ curing age, respectively, and the compressive strength is $53.7 \mathrm{MPa}$, 49.5 MPa, 56.4 MPa, and 47.2 $\mathrm{MPa}$, respectively. The second curing stage of concrete is as follows (7 14 d): the growth rate of concrete compressive strength is significantly higher than that of rebound number. The third curing stage of concrete is as follows (14 28d): compared with $7 \mathrm{~d}$ curing age, the rebound number of concretes double-mixed with fly ash and slag dosages of $15 \% 15 \%, 15 \% 30 \%, 20 \% 15 \%$, and $30 \% 15 \%$ increases by $7.22 \%, 13.01 \%, 3.66 \%$, and $14.32 \%$ at $28 \mathrm{~d}$ curing age, respectively, and the compressive strength increases by $10.39 \%, 20.65 \%, 7.77 \%$, and $23.35 \%$, respectively. The fourth curing stage of concrete is as follows (28 90 d): the rebound number of concretes double-mixed with fly ash and slag dosages of 15\%15\%, 15\%30\%, 20\%15\%, and $30 \% 15 \%$ is $50.9 \mathrm{MPa}, 50.4 \mathrm{MPa}, 50.9 \mathrm{MPa}$, and $50.1 \mathrm{MPa}$ at $90 \mathrm{~d}$ curing age, respectively, and the compressive strength is $63.9 \mathrm{MPa}, 64.8 \mathrm{MPa}, 65.1 \mathrm{MPa}$, and $64.4 \mathrm{MPa}$, respectively.

The rebound number and compressive strength of the concrete double-mixed with fly ash and slag 15\%30\% and $30 \% 15 \%$ are lower than the C50 concrete used in the project at $7 \mathrm{~d}$ curing age. At $28 \mathrm{~d}$ curing age, the rebound numbers of the concrete at each double-mixed with fly ash and slag dosages are not much different from that of the C50 concrete, while the compressive strength of concrete decreases by $8.95 \%, 8.32 \%, 6.71 \%$, and $10.69 \%$, respectively. At $90 \mathrm{~d}$ curing age, the rebound number of concretes under each double-mixed with fly ash and slag dosages decreases by $0.49 \%, 1.54 \%, 0.47 \%$, and $2.15 \%$, respectively, and the compressive strength decreases by $9.03 \%, 7.78 \%, 7.48 \%$, and $8.41 \%$, respectively. Additionally, there is a little difference in the rebound number and compressive strength of the concrete at various double-mixed dosages with fly ash and slag dosages, but the compressive strength of the concrete is lower than the C50 concrete used in this project. 


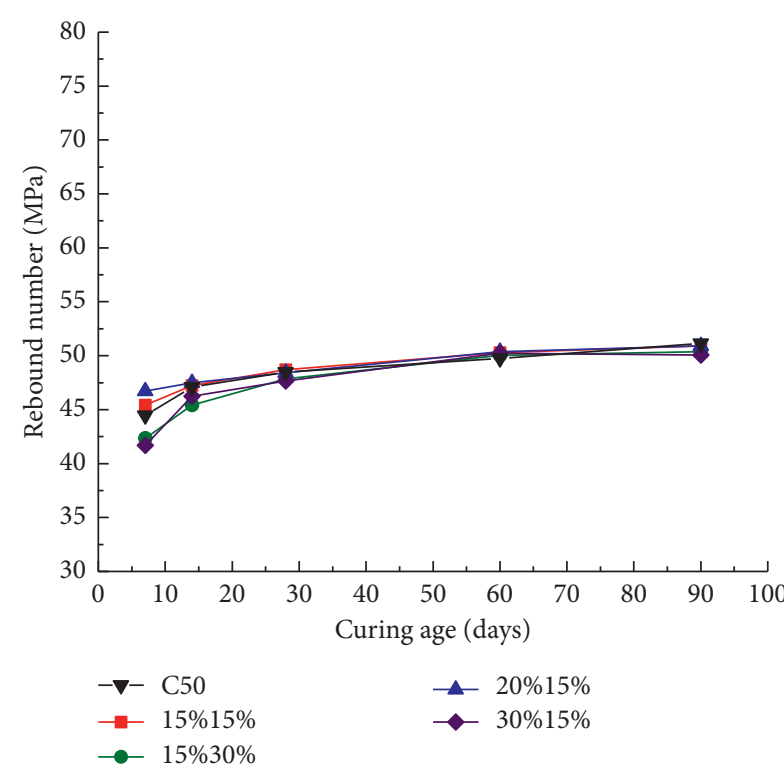

(a)

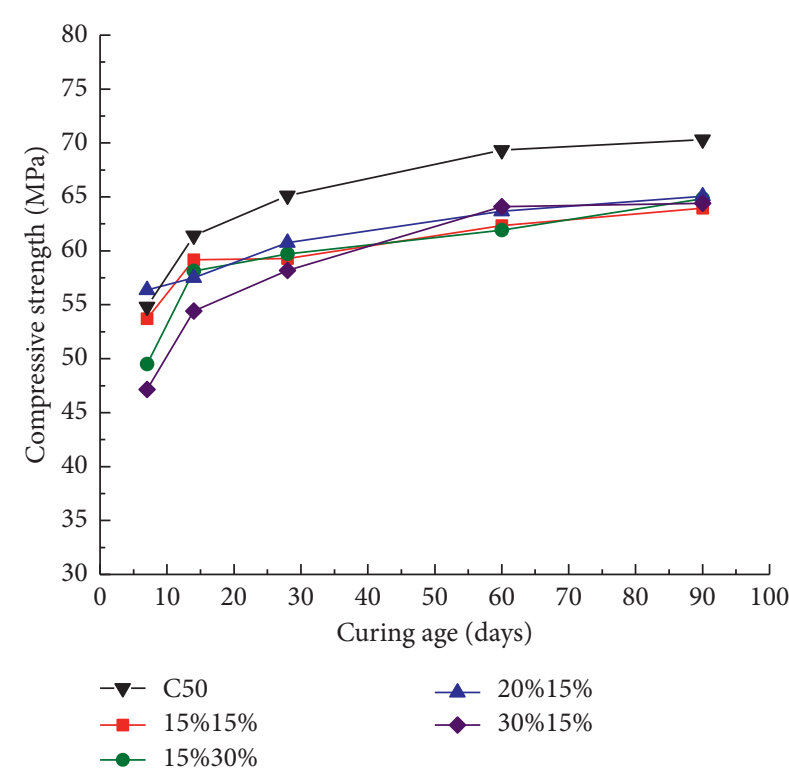

(b)

FIgURE 5: Rebound number and compressive strength of C50 concrete double-mixed with fly ash and slag at various curing ages: (a) rebound number and (b) compressive strength.

It shows that the compressive strength and early rebound number of concretes are reduced when the fly ash and slag double-mixed dosage is greater than $45 \%$. In the fourth curing stage of concrete, the double-mixed dosages with fly ash and slag have little effect on the rebound number of concretes, while the inhibitory effect on the compressive strength of concrete is more pronounced.

3.5. Testing Strength Curve of Concrete at $7 d$ Curing Age by Rebound Method. In order to estimate accurately the strength of concrete at early curing stage and to adapt to the construction requirements of actual construction period and quality control, four functional forms were selected to determine the regression model between rebound number and compressive strength of concrete at $7 \mathrm{~d}$ curing age in this work. The various testing strength curves of concrete at $7 \mathrm{~d}$ curing age were obtained (Figure 6), and these model formulas, correlation coefficient $\left(R^{2}\right)$, average relative error $(\delta)$, and relative standard error $\left(e_{r}\right)$ are listed in Table 4.

The error analysis shows that the fitting accuracy of the four functional forms all meet the requirements of the JGJ/T 23-2011 and exceed the national testing strength curve. Figure 6(a) shows that the compressive strength estimated by the power function fitting curve is significantly higher than the national testing strength curve under the same rebound number at $7 \mathrm{~d}$ curing age. The lower the rebound number is, the greater the difference of compressive strength that inferred from the two curves is. It indicates that it is lower than the early compressive strength of concrete estimated by the national testing strength curve, which is likely to cause waste of resources and to affect the construction period. The suggested testing strength curve formula by rebound method at $7 \mathrm{~d}$ curing age can be expressed as follows:

$$
f_{\mathrm{cu}}^{c}=33.65+10.93 \ln \left(R_{m}-36.99\right),
$$

where $R_{m}$ is rebound number of concrete specimens.

The average relative error is $4.2656 \%$. Compared with the national testing strength measurement curve, the estimation accuracy is improved by $35.99 \%$. Therefore, equation(2) can be used as a special testing strength curve by the rebound method at $7 \mathrm{~d}$ curing age.

3.6. Testing Strength Curve of Concrete at $90 d$ Curing Age by Rebound Method. In order to provide a reference for evaluating the development of compressive strength of concrete members from the $7 \mathrm{~d}$ to $90 \mathrm{~d}$ curing age, four functions were selected to fit the rebound number and compressive strength of concrete specimens. Then, the paper established a $90 \mathrm{~d}$ curing age special testing strength curve. The various testing strength models of concrete at $90 \mathrm{~d}$ are shown in Figure 7, and these model formulas, correlation coefficient $\left(R^{2}\right)$, average relative error $(\delta)$, and relative standard error $\left(e_{r}\right)$ are listed in Table 5.

Through errors analysis, the testing strength curve formula for $90 \mathrm{~d}$ curing age can be expressed as follows:

$$
f_{\mathrm{cu}}^{c}=-1752.226+115.605 R_{m}-2.496 R_{m}^{2}+0.0182 R_{m}^{3} \text {. }
$$

The average relative error is $4.8544 \%$, which decreases by $20.26 \%$ compared to that of the national testing strength curve. Therefore, equation(3) can be used as a special testing strength curve at $90 \mathrm{~d}$ curing age by rebound method. 


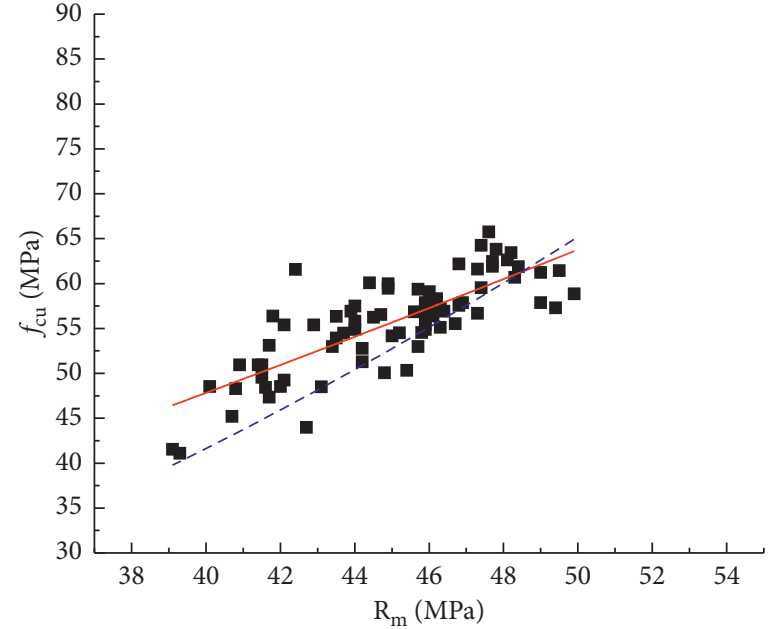

Power testing strength curve _ National testing strength curve

(a)

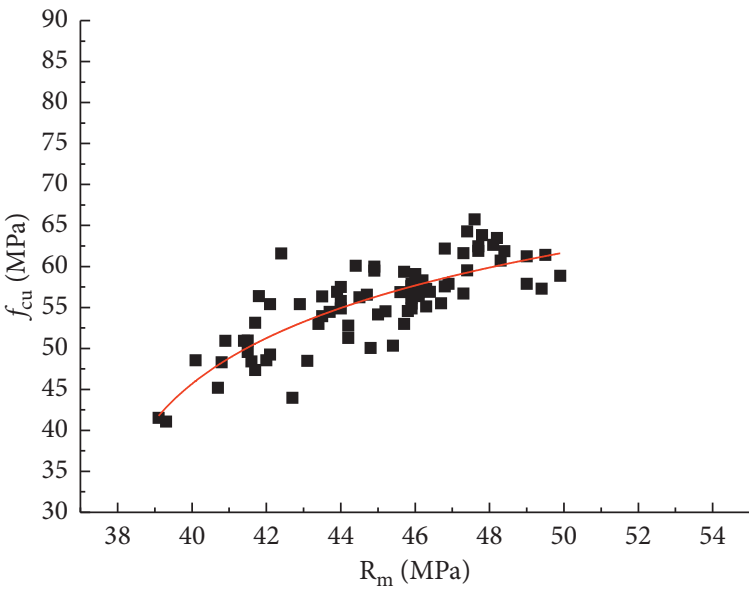

_ Logarithmic testing strength curve

(c)

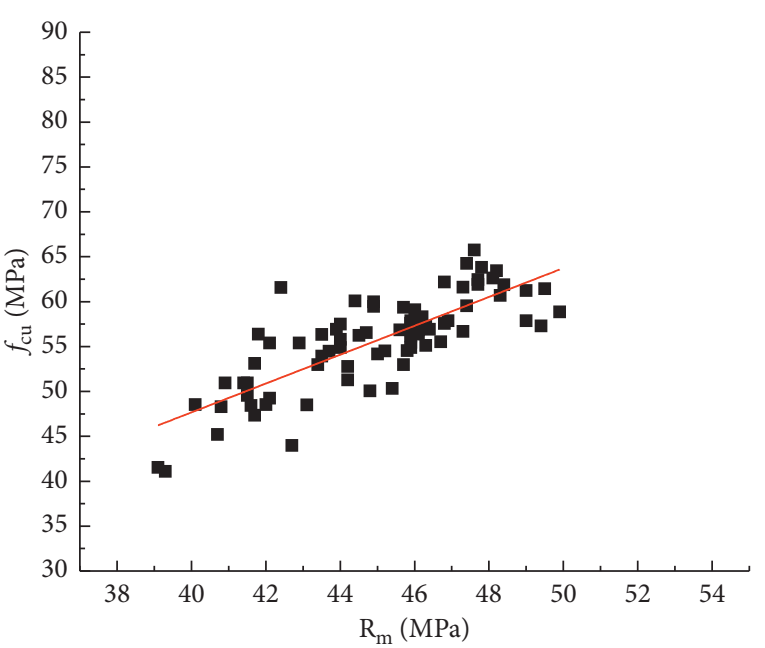

___ Linear testing strength curve

(b)

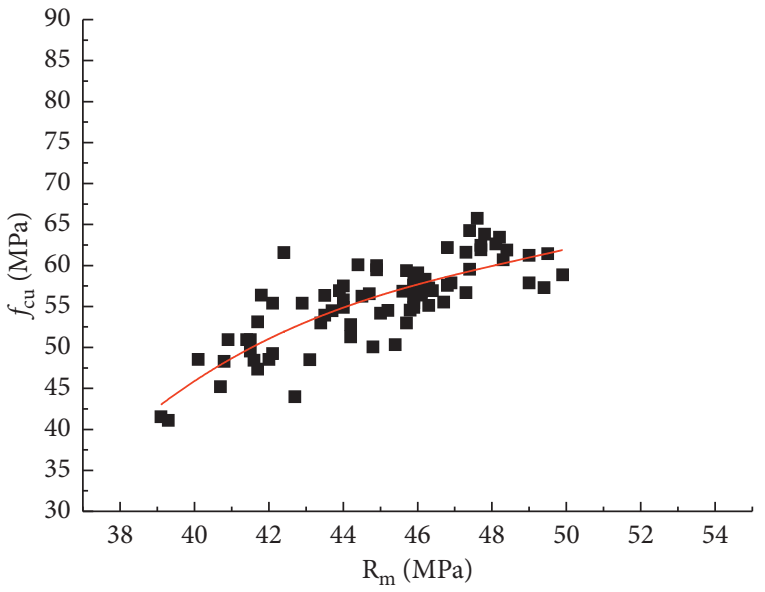

- Polynomial testing strength curve

(d)

FIGURE 6: The special strength testing curve of concrete at $7 \mathrm{~d}$ curing age: (a) curve fitting using power function, (b) curve fitting using linear function, (c) curve fitting using logarithmic function, and (d) curve fitting using polynomial function.

TABLE 4: The regression formulas of special testing strength curve at $7 \mathrm{~d}$ curing age.

\begin{tabular}{lcrr}
\hline Function form & Formula & $R^{2}$ & $\delta(\%)$ \\
\hline National testing strength curve & $f_{\mathrm{cu}}^{c}=0.025 R_{m}^{2.0108}$ & - & 6.6635 \\
Power & $f_{\mathrm{cu}}^{c}=0.411 R_{m}^{1.289}$ & 0.62463 & 4.5722 \\
Linear & $f_{\mathrm{cu}}^{c}=-16.61+1.61 R_{m}$ & 0.62697 & 4.5578 \\
Logarithmic & $f_{\mathrm{cu}}^{c}=33.65+10.93 \ln \left(R_{m}-36.99\right)$ & 0.65505 & 4.2656 \\
Polynomial & $f_{\mathrm{cu}}^{c}=-942.90+59.44 R_{m}-1.19 R_{m}^{2}+0.008 R_{m}^{3}$ & 0.65076 & 4.9215 \\
\hline
\end{tabular}

3.7. Verification of Testing Strength Curve of Concrete by Rebound Method. In order to verify the accuracy of the special testing strength curves at $7 \mathrm{~d}$ and $90 \mathrm{~d}$ curing age, three sets of $\mathrm{C} 35, \mathrm{C} 40$, and $\mathrm{C} 50$ concrete cubes $(150 \mathrm{~mm} \times 150 \mathrm{~mm} \times 150 \mathrm{~mm})$ were prepared. The specimens were removed from the mold, and they were further cured at the bridge construction site for 7 days and 28 days. The estimation results of equations (2) and (3) are shown in Tables 6 and 7, respectively.

It can be seen from Table 6 that the maximum relative error of concrete compressive strength is $3.84 \%$, which is estimated by the special testing strength curve of $7 \mathrm{~d}$ curing 


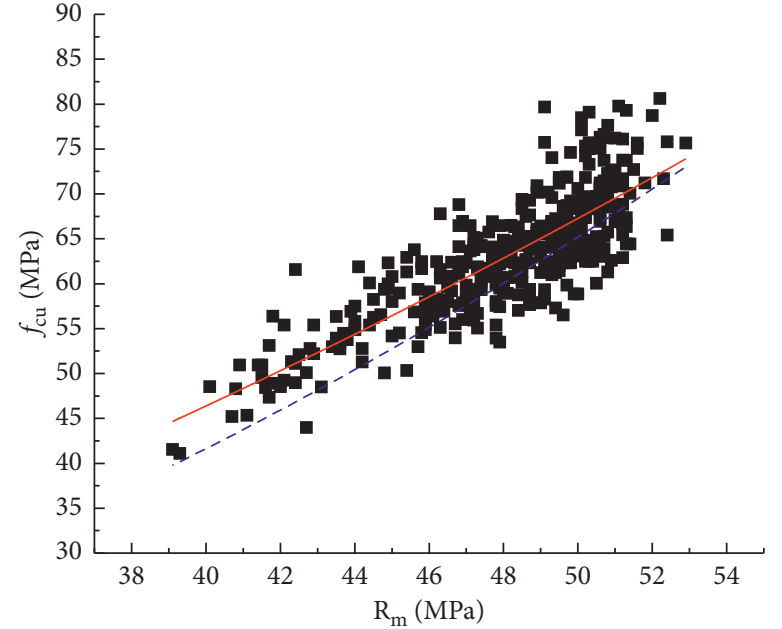

- Power testing strength curve - - - National testing strength curve

(a)

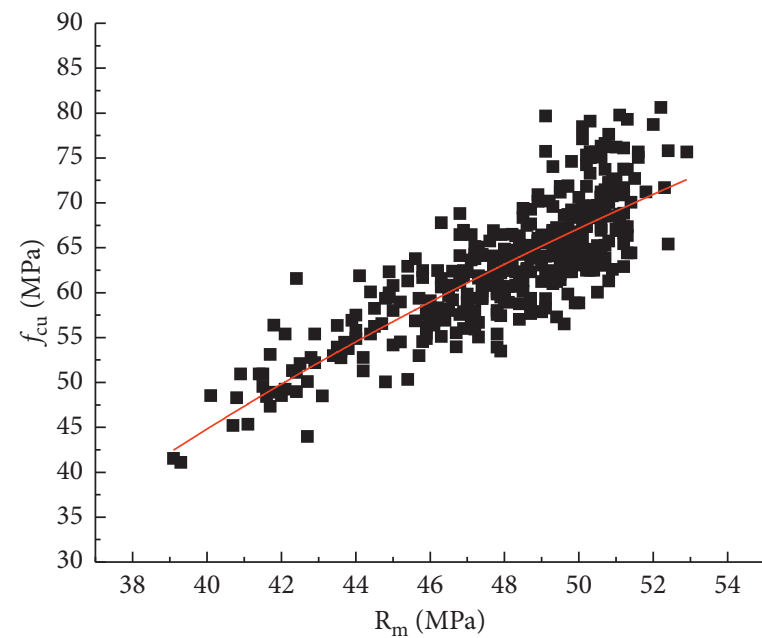

__ Logarithmic testing strength curve

(c)

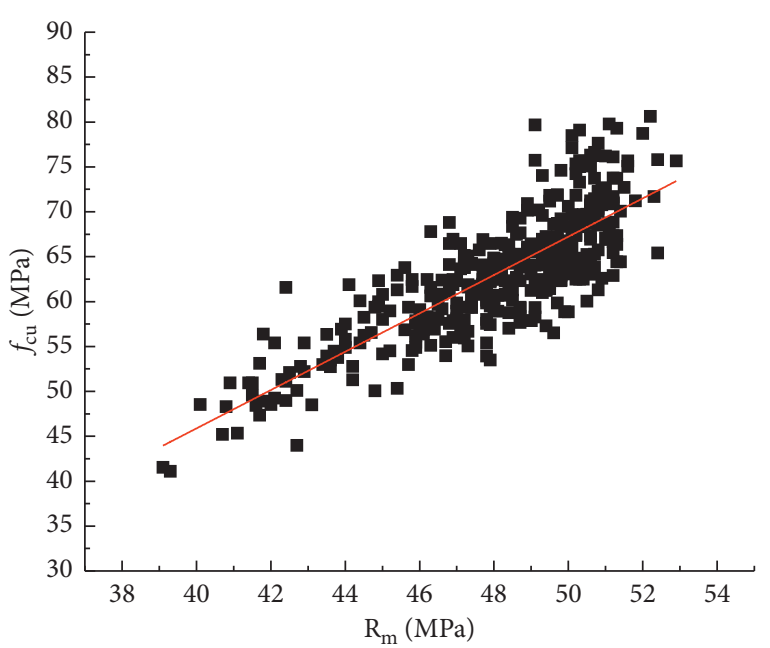

__ Linear testing strength curve

(b)

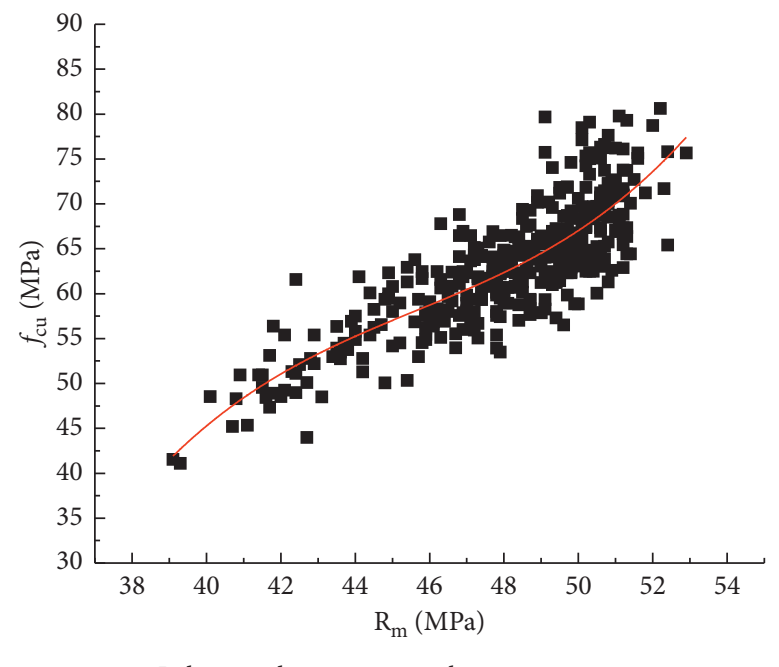

- Polynomial testing strength curve

(d)

Figure 7: The special strength testing curve of concrete at $90 \mathrm{~d}$ curing age: (a) curve fitting using power function, (b) curve fitting using linear function, (c) curve fitting using logarithmic function, and (d) curve fitting using polynomial function.

TABLE 5: The regression formulas of special testing strength curve at $90 \mathrm{~d}$ curing age.

\begin{tabular}{|c|c|c|c|c|}
\hline Function form & Formula & $R^{2}$ & $\delta(\%)$ & $e_{r}(\%)$ \\
\hline National testing strength curve & $f_{\mathrm{cu}}^{c}=0.025 R_{m}^{2.0108}$ & - & 6.0881 & 7.4739 \\
\hline Power & $f_{\mathrm{cu}}^{c}=0.100 R_{m}^{1.6659}$ & 0.67176 & 4.9355 & 6.2393 \\
\hline Linear & $f_{\mathrm{cu}}^{c}=-39.521+2.135 R_{m}$ & 0.66998 & 4.9483 & 6.2498 \\
\hline Logarithmic & $f_{\mathrm{cu}}^{c}=380.339 \ln \left(0.305 \ln \left(R_{m}\right)\right)$ & 0.66466 & 4.9847 & 6.2921 \\
\hline Polynomial & $f_{\mathrm{cu}}^{c}=-1752.226+115.605 R_{m}-2.496 R_{m}^{2}+0.0182 R_{m}^{3}$ & 0.67934 & 4.8544 & 6.1561 \\
\hline
\end{tabular}

age. It can be seen from Table 7 that the maximum relative errors of concrete compressive strength are $6.63 \%$ and $4.61 \%$ at $7 \mathrm{~d}$ and $28 \mathrm{~d}$ estimated by the special testing strength curve of $90 \mathrm{~d}$ age, respectively. All of those show that the special testing strength curves of $7 \mathrm{~d}$ and $90 \mathrm{~d}$ established in this work have high accuracy and can assess the compressive strength of Yanchong expressway concrete members at various curing ages. 
TABLE 6: Estimation results of $7 \mathrm{~d}$ curing age special testing strength curve.

\begin{tabular}{|c|c|c|c|c|c|c|}
\hline Mix & No. & $\begin{array}{l}\text { Curing age } \\
\text { (d) }\end{array}$ & $\begin{array}{l}\text { Rebound number } \\
(\mathrm{MPa})\end{array}$ & $\begin{array}{c}\text { Estimation value of compressive } \\
\text { strength }(\mathrm{MPa})\end{array}$ & $\begin{array}{l}\text { Destructive compressive } \\
\text { strength }(\mathrm{MPa})\end{array}$ & $\begin{array}{c}\text { Relative error } \\
(\%)\end{array}$ \\
\hline \multirow{3}{*}{ C35 } & 1 & 7 & 42.1 & 51.4 & 49.5 & 3.84 \\
\hline & 2 & 7 & 39.3 & 42.8 & 41.7 & 2.64 \\
\hline & 3 & 7 & 39.1 & 41.8 & 42.5 & 1.65 \\
\hline \multirow{3}{*}{ C40 } & 1 & 7 & 43.1 & 53.4 & 51.5 & 3.69 \\
\hline & 2 & 7 & 44.2 & 55.2 & 53.3 & 3.56 \\
\hline & 3 & 7 & 44.8 & 56.1 & 54.8 & 2.38 \\
\hline \multirow{3}{*}{ C50 } & 1 & 7 & 44.6 & 55.8 & 57.3 & 2.62 \\
\hline & 2 & 7 & 44.9 & 56.3 & 54.5 & 3.30 \\
\hline & 3 & 7 & 46.2 & 57.9 & 56.8 & 1.94 \\
\hline
\end{tabular}

TABLE 7: Estimation results of $90 \mathrm{~d}$ curing age special testing strength curve.

\begin{tabular}{|c|c|c|c|c|c|c|}
\hline Mix & No. & $\begin{array}{l}\text { Curing age } \\
\text { (d) }\end{array}$ & $\begin{array}{l}\text { Rebound number } \\
(\mathrm{MPa})\end{array}$ & $\begin{array}{c}\text { Estimation value of compressive } \\
\text { strength }(\mathrm{MPa})\end{array}$ & $\begin{array}{c}\text { Destructive compressive } \\
\text { strength }(\mathrm{MPa})\end{array}$ & $\begin{array}{c}\text { Relative error } \\
(\%)\end{array}$ \\
\hline \multirow{6}{*}{ C35 } & 1 & 7 & 42.1 & 48.9 & 49.5 & 1.21 \\
\hline & 2 & 7 & 39.3 & 40.7 & 41.7 & 2.40 \\
\hline & 3 & 7 & 39.1 & 40.0 & 42.5 & 5.88 \\
\hline & 4 & 28 & 42.4 & 49.5 & 50.1 & 1.20 \\
\hline & 5 & 28 & 42.7 & 50.1 & 51.3 & 2.34 \\
\hline & 6 & 28 & 43.8 & 52.2 & 52.7 & 0.95 \\
\hline \multirow{6}{*}{ C40 } & 1 & 7 & 43.1 & 50.9 & 51.5 & 1.17 \\
\hline & 2 & 7 & 44.2 & 52.8 & 53.3 & 0.94 \\
\hline & 3 & 7 & 44.8 & 53.8 & 54.8 & 1.82 \\
\hline & 4 & 28 & 48.0 & 58.8 & 59.3 & 0.84 \\
\hline & 5 & 28 & 44.8 & 53.8 & 56.4 & 4.61 \\
\hline & 6 & 28 & 47.9 & 58.6 & 59.2 & 1.01 \\
\hline \multirow{6}{*}{ C50 } & 1 & 7 & 44.6 & 53.5 & 57.3 & 6.63 \\
\hline & 2 & 7 & 44.9 & 53.9 & 54.5 & 1.10 \\
\hline & 3 & 7 & 46.2 & 55.9 & 56.8 & 1.58 \\
\hline & 4 & 28 & 48.7 & 60.1 & 59.3 & 1.35 \\
\hline & 5 & 28 & 49.1 & 60.9 & 60.3 & 1.00 \\
\hline & 6 & 28 & 48.5 & 59.7 & 60.4 & 1.16 \\
\hline
\end{tabular}

\section{Conclusion}

Taking Yanchong Expressway as the research object, this paper makes an experimental study on the special testing strength curve for compressive strength evaluation by rebound method at $7 \mathrm{~d}$ and $90 \mathrm{~d}$ curing age. The main conclusions are as follows:

(1) The early curing stage is the main formation period of concrete strength. More attention should be paid to whether the curing conditions of concrete members meet the requirements at the early curing stages. In this paper, the compressive strength of concrete at $7 \mathrm{~d}$ can exceed $70 \%$ at the 90 d. For Yanchong Expressway or other projects with tight construction period in this area, the compressive strength at the age of $7 \mathrm{~d}$ can be used to predict the compressive strength at the age of $90 \mathrm{~d}$.

(2) Fly ash and slag are beneficial to the growth of concrete rebound number but cannot contribute to the growth of concrete compressive strength (except for fly ash single-mixed with 15\% dosage).
(3) The suggested testing strength curve formula of $7 d$ curing age by rebound method can be expressed as $f_{\mathrm{cu}}^{c}=33.65+10.93 \ln \left(R_{m}-36.99\right)$. The average relative error is $4.2656 \%$, the estimation accuracy is improved by $35.99 \%$ compared to the national testing strength curve.

(4) The suggested testing strength curve formula of $90 \mathrm{~d}$ curing age by rebound method can be expressed as $f_{\text {cu }}$ $\stackrel{c}{=}-1752.226+115.605 R_{m}-2.496 R_{m}^{2}+0.0182 R_{m}^{3}$. The average relative error is $4.8544 \%$, which decreases by $20.26 \%$ compared to that of the national testing strength curve.

\section{Data Availability}

The data used to support the findings of this study are available from the corresponding author upon request.

\section{Conflicts of Interest}

The authors declare that they have no conflicts of interest regarding the publication of this study. 


\section{Acknowledgments}

This work was supported by the Science and Technology Research Project of Hebei Provincial Transport Department of China (Grant no. YC-201922).

\section{References}

[1] Y. Tan, H. Yu, R. Mi, and Y. Zhang, "Compressive strength evaluation of coral aggregate seawater concrete (CAC) by non-destructive techniques," Engineering Structures, vol. 176, pp. 293-302, 2018.

[2] D. Kocáb, P. Misák, and P. Cikrle, "Characteristic curve and its use in determining the compressive strength of concrete by the rebound hammer test," Materials, vol. 12, no. 17, pp. 1-17, 2019.

[3] T. Xu and J. Li, "Assessing the spatial variability of the concrete by the rebound hammer test and compression test of drilled cores," Construction and Building Materials, vol. 188, pp. 820-832, 2018.

[4] A. Brencich, R. Bovolenta, V. Ghiggi, D. Pera, P. Redaelli, and A. Gloria, "Rebound hammer test: an investigation into its reliability in applications on concrete structures," Advances in Materials Science and Engineering, vol. 2020, Article ID 6450183, 11 pages, 2020.

[5] H.-S. Shang, T.-H. Yi, and L.-S. Yang, "Experimental study on the compressive strength of big mobility concrete with nondestructive testing method," Advances in Materials Science and Engineering, vol. 2012, Article ID 345214, 6 pages, 2012.

[6] M. Alexa, P. Misák, and D. Kocáb, "Creating a specific regression model to determine the compressive strength of concrete through NDT, " in Proceedings of the Special Concrete and Composites 2020: 17th International Conference, San Francisco, California, USA, 2021.

[7] K. Szilágyi, A. Borosnyói, and I. Zsigovics, "Rebound surface hardness of concrete: introduction of an empirical constitutive model," Construction and Building Materials, vol. 25, no. 5, pp. 2480-2487, 2011.

[8] N. Pereira and X. Romão, "Assessing concrete strength variability in existing structures based on the results of NDTs," Construction and Building Materials, vol. 173, pp. 786-800, 2018.

[9] K. Rashid and R. Waqas, "Compressive strength evaluation by non-destructive techniques: an automated approach in construction industry," Journal of Building Engineering, vol. 12, pp. 147-154, 2017.

[10] D. Samson and T. M. Omoniyi, "Correlation between nondestructive testing (NDT) and destructive testing (DT) of compressive strength of concrete," International Journal of Engineering Science Invention, vol. 3, no. 9, pp. 12-17, 2014.

[11] H. R. Kumavat, N. R. Chandak, and I. T. Patil, "Factors influencing the performance of rebound hammer used for non-destructive testing of concrete members: a review," Case Studies in Construction Materials, vol. 14, pp. 1-12, 2021.

[12] M. Alwash, D. Breysse, Z. M. Sbartaï, K. Szilágyi, and A. Borosnyói, "Factors affecting the reliability of assessing the concrete strength by rebound hammer and cores," Construction and Building Materials, vol. 140, pp. 354-363, 2017.

[13] L. Wang, F. Guo, Y. Lin, H. Yang, and S. W. Tang, "Comparison between the effects of phosphorous slag and fly ash on the C-S-H structure, long-term hydration heat and volume deformation of cement-based materials," Construction and Building Materials, vol. 250, Article ID 118807, 2020.
[14] L. Wang, M. M. Jin, F. X. Guo, Y. Wang, and S. W. Tang, "Pore structural and fractal analysis of the influence of fly ash and silica fume on the mechanical property and abrasion resistance of concrete," Fractals, vol. 29, no. 2, Article ID 2140003, 2021.

[15] L. Wang, R. Luo, W. Zhang, M. Jin, and S. Tang, "Effects of fineness and content of phosphorus slag on cement hydration, permeability, pore structure and fractal dimension of concrete," Fractals, vol. 26, 2021.

[16] L. Wang, M. Jin, S. Zhou, S. Tang, and X. Lu, "Investigation of microstructure of C-S-H and micro-mechanics of cement pastes under NH4NO3 dissolution by 29Si MAS NMR and microhardness," Measurement, vol. 185, Article ID 110019, 2021.

[17] İ.A. A. Niş, "Compressive strength performance of alkali activated concretes under different curing conditions," Periodica Polytechnica: Civil Engineering, vol. 65, no. 2, pp. 556-565, 2021.

[18] H. Liu, S. Zhao, and J. Wang, "Study on special strength curve of rebound method for concrete evaluation of Oujiang River Bridge," China Civil Engineering Journal, vol. 48, pp. 41-48, 2015.

[19] A. Vatani Oskouei, R. Nazari, and M. Houshmand Khaneghahi, "Laboratory and in situ investigation of the compressive strength of CFRD concrete," Construction and Building Materials, vol. 242, pp. 1-10, 2020.

[20] Technical Specification for Inspecting of concrete Compressive Strength by Rebound Method, China Architecture \& Building Press, Beijing, China, 2011.

[21] L. Wang, F. X. Guo, H. M. Yang, Y. Wang, and S. W. Tang, "Comparison of fly ash, pva fiber, mgo and shrinkage-reducing admixture on the frost resistance of face slab concrete via pore structural and fractal analysis," Fractals, vol. 29, no. 2, 2021. 